\title{
BMJ Open Qualitative analysis of the impact of the SARS-CoV-2 pandemic response on paediatric health services in North of Scotland and North of England
}

\author{
Erica W Gadsby (10 , ${ }^{1,2}$ Floor Christie-de Jong (1) , ${ }^{3}$ Sunil Bhopal, ${ }^{4,5}$ \\ Heather Corlett, ${ }^{6}$ Stephen Turner ${ }^{7,8}$
}

To cite: Gadsby EW, Christiede Jong F, Bhopal S, et al. Qualitative analysis of the impact of the SARS-CoV-2 pandemic response on paediatric health services in North of Scotland and North of England. BMJ Open 2022;12:e056628. doi:10.1136/ bmjopen-2021-056628

- Prepublication history and additional supplemental material for this paper are available online. To view these files, please visit the journal online (http://dx.doi.org/10.1136/ bmjopen-2021-056628)

Received 24 August 2021 Accepted 12 January 2022

Check for updates

(C) Author(s) (or their employer(s)) 2022. Re-use permitted under CC BY-NC. No commercial re-use. See rights and permissions. Published by BMJ.

For numbered affiliations see end of article.

Correspondence to

Dr Erica W Gadsby;

E.Gadsby@kent.ac.uk

\section{ABSTRACT}

Objective To capture the extent and impact of changes in the delivery of child health services in the UK, resulting from the SARS-CoV-2 pandemic response, from the perspectives of a range of child healthcare providers. Setting National Health Service commissioned/delivered healthcare services in two regional settings in the UK: North of Scotland (NOS) and North East and North Cumbria (NENC) in England.

Participants Purposive sample of 39 child healthcare professionals including paediatricians, community/ specialist nurses, allied health professionals and mental health professionals, from across the two regions (22 in NOS, 17 in NENC).

Methods Semistructured qualitative interviews conducted via telephone between June and October 2020, fully transcribed and analysed in NVivo V.11 using thematic analysis.

Results Extensive changes across a range of paediatric services were rapidly implemented to support the pandemic response and ongoing healthcare delivery. New ways of working emerged, principally to control the spread of the virus. Keeping users and their families out of hospital was an urgent driver for change. The changes had considerable impact on the health and well-being of staff with many experiencing radical changes to their working conditions and roles. However, there were some positive changes noted: some practitioners felt empowered and listened to by decision makers; some of the usual bureaucratic barriers to change were lifted; staff saw improved collaboration and joint working across the system; and some new ways of working were seen to be more efficient. Interviewees perceived the implications for children and their families to be profound, particularly with regard to self-care, relationships with practitioners and timely access to services.

Conclusions Despite the challenges experienced by staff, the pandemic provided an opportunity for positive, lasting change. It is vital to capitalise on this opportunity to benefit patient outcomes and to 'build back' services in a more sustainable way.

\section{INTRODUCTION}

Health service delivery around the world has changed since the WHO declared that the
Strengths and limitations of this study

- This qualitative study included unique and in-depth perspectives of child healthcare providers, who were under-represented in the SARS-CoV-2 pandemic response.

- Participants were purposively sampled to ensure a diverse range of child healthcare providers and wider perspectives were included.

- Data were collected between June and October 2020, between the UK's first and second waves of SARS-CoV-2.

- Data were collected across two large geographical regions in England and Scotland, enabling comparisons and similarities to be observed in different National Health Service systems.

- Given the changing nature of the pandemic response and the consequent changes in services and service delivery, this study presents a snapshot in time within two regions of the UK.

SARS-CoV-2 outbreak was a pandemic on 11 March 2020. Child health services in the UK are no exception and, despite the virus resulting in much less morbidity and mortality in children than in adults, ${ }^{12}$ service delivery was transformed to accommodate the emergency pandemic response. Elements of the response, including school closures, social distancing measures and staff redeployment, have inevitably impacted on child health service delivery. These changes occurred rapidly. They present both opportunities for future service improvements, and costs and possible unintended consequences. Their impact and the opportunities for improving care have yet to be fully understood and exploited.

This study, conducted during the initial stages of the UK pandemic (April to December 2020), examined some of the key changes to and innovations in children's healthcare service delivery occurring during 
that time, and child healthcare providers' perspectives and experiences of these changes. While not an original aim of the study, our data also enabled us to explore the impact of the pandemic on staff health and well-being. It focused on the National Health Service (NHS) commissioned/delivered healthcare services in two regional settings in the UK-North of Scotland (NOS) and North East and North Cumbria (NENC) in England. The qualitative case study approach generated a rich account of the situation in two geographical regions and enabled us to explore meanings and implications relevant to each region, and to compare and illuminate aspects of difference. Both regions had strong, multiprofessional community and academic networks through prepandemic service improvement programmes (to which the researchers were connected), which played an important role in shaping this research, facilitating access to information and discussing emerging themes.

\section{METHODS}

\section{Setting}

The NOS encompasses six health boards, three of which are on remote islands. The provision of generalist and specialist paediatric services for the widely dispersed population is challenging. Each board is autonomous, but they are also codependent for some specialist children's services, many of which are provided on a managed network basis from mainland boards. Staff recruitment and retention is a particular challenge in this region. Across NENC, four integrated care partnerships (ICPs) are working together to improve health outcomes. ICPs are formal partnerships of provider organisations that collaborate to deliver care. Life expectancy in this region remains among the poorest in England, driving much of the pressure on the local health and care system with record numbers of people accessing services year on year. $^{34}$

\section{Sample and recruitment}

We recruited a purposive sample of participants in each region through open and targeted invitations using existing networks, and using the snowball method, ${ }^{5}$ aiming for a range of participants across key health service categories (general and acute paediatrics, mental health and therapy services) and across the medical, nursing and allied health professions. Sampling began in May 2020 and finished when data saturation was reached in key themes. We had little difficulty reaching respondents; overall, people were keen to talk about their experiences.

\section{Data collection}

In-depth, semistructured telephone interviews were conducted during and immediately following the critical period of the SARS-CoV-2 response. This method allowed participants to recall, recount and reflect on their experiences as health practitioners since the pandemic began, and elicited rich data. EWG conducted all interviews in
NOS between 10 June and 26 August 2020, spanning phases 1, 2 and 3 of the Scotland transition out of lockdown 'Route Map' ${ }^{6}$ In NENC, interviews were divided between three researchers who received specific training. Participants were interviewed between 2 July and 8 October 2020, spanning the second and third phases of England's NHS response to SARS-CoV-2. ${ }^{7}$ The interview guide was constructed in consultation with key stakeholders. Interviews examined the participants' role and changes in that since the start of the pandemic; changes in the services participants were involved in managing or providing; their thoughts about impacts of these changes; and their thoughts about the future, and changes they might want to retain (see online supplemental file 1). Interviews were audio recorded with consent, and transcribed verbatim. EWG, FC-dJ and SB reviewed the audio files following interviews and modified the interview guide as required, for example, to explore specific ideas with subsequent participants. Interviews mostly lasted about an hour, with the shortest being $30 \mathrm{~min}$. They continued until data saturation (the final two interviews in each region did not elicit new idea elements).

\section{Patient and public involvement}

The research questions and study design were developed with input from the child health networks in each area, made up of health, social care and education professionals, third sector organisations and patient advocates. Findings were discussed with network members in a webinar (recorded and shared via YouTube), and disseminated via network briefings, newsletters and a final report. No patients were directly involved in this study.

\section{Data analysis}

Transcripts were analysed in NVivo V.11 using thematic analysis to inductively develop a pattern of themes and meanings from participants' views of the situation. ${ }^{8}$ EWG, FC-dJ and SB independently coded an initial set of transcripts then reviewed, discussed and agreed themes and relationships before coding the remaining transcripts. Synthesised data in the form of thematic statements from both regions were combined using a thematic analysis framework in MS Word. ${ }^{9}$ EWG reviewed the data using a framework for transformative social innovation ${ }^{10}$ which was used to identify, understand and analyse innovations in the following categories:

- New social relations (agents in different contexts working together in different ways).

- New ways of doing (new technologies, practices).

- New ways of organising (new modes of organising, forms of governance, formats, institutions).

- New ways of framing (new values, meanings, visions).

- New ways of knowing (new knowledge, competence, cognition).

Preliminary analyses were presented via webinar on 25 November 2020 to 35 stakeholders from NENC and 30 from NOS, representing a range of service providers and commissioners from NHS organisations, local authorities 
Table 1 Breakdown of North of Scotland participants by locality and profession (identification code in brackets)

\begin{tabular}{|c|c|c|c|c|c|c|c|}
\hline & $\begin{array}{l}\text { NHS } \\
\text { Grampian }\end{array}$ & NHS Highland & NHS Tayside & $\begin{array}{l}\text { NHS Western } \\
\text { Isles }\end{array}$ & $\begin{array}{l}\text { NHS } \\
\text { Orkney }\end{array}$ & $\begin{array}{l}\text { NHS } \\
\text { Shetland }\end{array}$ & Total \\
\hline Paediatrician & 1 (NOSO04) & 2 (NOS007, NOS014) & 1 (NOSO05) & 1 (NOS015) & - & - & 5 \\
\hline CAMHS & - & 2 (NOS009, NOS011) & 2 (NOS002, NOS008) & 1 (NOS019) & - & 1 (NOSO06) & 6 \\
\hline Total & 4 & 6 & 5 & 3 & 2 & 2 & 22 \\
\hline
\end{tabular}

CAMHS, child and adolescent mental health services; NHS, National Health Service.

and third sector organisations. Participants were invited to ask questions and discuss findings and analysis. This valuable discussion guided further analysis and discussion of the data.

\section{RESULTS}

The sample comprised 39 healthcare professionals: 22 participants in NOS (18 male; 4 female); 17 in NENC (4 male; 13 female). See tables 1 and 2; each participant was assigned an identifying code.

Two overarching themes emerged: (1) key changes and (2) perceived impact of these changes, each with a number of subthemes, as summarised below.

\section{Theme 1: key changes}

The key changes that took place were in relation to supporting the pandemic response and predominantly comprised: (1) remote and digital working, (2) protecting routine services, (3) supporting the mental health of staff and the public, and (4) changes in the ways staff were working.

\section{Remote and digital working}

The most frequently mentioned change was the move to online service delivery. Online video consultation programmes were being used to, for example, keep families remotely involved in inpatient treatment; run outpatient and multidisciplinary team clinics; deliver mental health support; deliver a range of therapy support; and communicate the results of diagnostic tests. Microsoft Teams was being used widely for formal and informal interprofessional communications and to attend national and international professional development sessions. In most community-based services there was unsurprisingly less home visiting and an increased use of the telephone.

For Paeds they moved swiftly to video consultation and the only essential statutory face-to-face was done on our non-acute hospital sites. (NE013)

\section{Protecting routine services}

Several changes were captured in scheduled and unscheduled care. Alongside the use of digital technology, there were efforts to shift hospital-based activities into the community. For example, in Grampian, community hubs were established where scheduled care investigations could be conducted in lieu of hospital. This helped improve the information that specialists received prior to consultations. In NENC Central, community clinics were run to prevent emergency department referrals, and 'hot

Table 2 Breakdown of North of England and North Cumbria participants by locality and profession (identification code in brackets)

\begin{tabular}{|c|c|c|c|c|c|c|}
\hline & Cumbria & $\begin{array}{l}\text { NorthEast } \\
\text { South }\end{array}$ & NorthEast North & $\begin{array}{l}\text { NorthEast } \\
\text { Central }\end{array}$ & Regional & Total \\
\hline Paediatrician & 1 (NE007) & 1 (NE006) & - & 1 (NE013) & 2 (NE001, NE012) & 5 \\
\hline CAMHS & 1 (NE016) & 1 (NE003) & - & - & - & 2 \\
\hline $\begin{array}{l}\text { Allied health } \\
\text { professionals }\end{array}$ & 1 (NE002) & - & 2 (NE005, NE017) & - & - & 3 \\
\hline GP & - & 1 (NE015) & 1 (NE009) & - & - & 2 \\
\hline Total & 4 & 4 & 4 & 2 & 3 & 17 \\
\hline
\end{tabular}

CAMHS, child and adolescent mental health services; GP, general practitioner. 
hubs' set up to assess children and adults for fever and cough outside of hospital. Paediatricians in both regions worked closely with pharmacists and general practitioners (GPs) to ensure prescriptions could be issued locally away from the hospital.

Efforts were also made to support primary care. For example, in Tayside, a new stream was developed at the SARS-CoV-2 out-of-hours assessment hub with paediatricians rather than GPs. Elsewhere in the system, other changes were introduced to help prevent hospital admissions. For example, in Highland, there was a significant service redesign to ensure child and adolescent mental health services (CAMHS) could respond immediately, in the community, to emergency cases. Their usual therapeutic work was reduced in favour of more staff working acutely, staffing a rota to provide 7 days a week, 24 hours a day emergency access to a CAMHS professional.

We switched to a service that was trying to keep everyone out of hospital. (NOS009)

So we set up a hot hub ... we saw children and adults with temperatures, so any child, any adult with a cough or a temperature came to our hot hub ... to prevent them going to hospital, and we monitored them and assessed them in the community and kept them there. (NE010)

While several new arrangements were tested during the pandemic, the situation was unusual in that many parents / patients were reluctant to approach health services given the heightened risk of infection. Some changes therefore were later withdrawn due to low numbers of patients.

Participants reported many changes aiming to support services that were seeing a surge in workload. Several interviewees explained that their junior doctors were redeployed to the adult SARS-CoV-2 response. In Grampian, several specialty doctors, specialist nurses and allied health professionals from the community child health department were also redeployed into acute care provision. An occupational therapist in Grampian explained that 'when we first went into lockdown, half of our staff were redeployed onto the wards' (NOS016). In Tayside, two paediatric dieticians were redeployed to the SARSCoV-2 dietetics team. In Highland, some specialist and community nurses were redeployed to help the hospital. However, while the community paediatricians were 'inducted and trained to step up a level whether it was medical grade or consultants' (NOS007), they ultimately were not needed. They did, however, take over running the child protection rota to relieve pressures on the hospital. Interviewees in NENC North and Central in leadership and operational management roles explained that redeployment to adult services was discussed and planned, although not always executed as the need did not arise.

While there was an initial inclination to use paediatric staff in adult services and to shift community resources to the acute sector, there was also a recognition of the need to protect non-SARS-CoV-2 services for children. These services changed in response to reduced staffing caused by shielding, sickness and redeployments. In Grampian, an oncologist described the changes in pathways required to enable them to continue providing services to patients with cancer. This team made multiple changes (eg, to theatre pathways and postoperative recovery) to enable them to continue with service provision and to get through their backlog of patients. For some vulnerable patients requiring ongoing care, locations and pathways of care were sometimes changed to help protect patients from potential infection. In several areas, interviewees described arguing strongly that staff performing certain core functions, like child protection and CAMHS, should not be redeployed.

The thing that came out of it was basically we are not redeploying our child protection team ... we are not moving that group of staff. That has to be a core function. (NOS005)

\section{Supporting the mental health of staff and the public}

In both regions, participants described innovations to support the well-being of both staff and the public. In NENC, CAMHS offered psychological first aid to all clinical and leadership staff. The Medical Psychology Team at South Tees stopped usual work and created a whole service to support staff working in acute settings. One of the paediatricians (NE013) deployed to adult services described how the leadership team walked the wards to support staff. In the Western Isles, a 'psychological hub' was established providing a phone line through the local authority, advertised in the newspapers, for people impacted by SARS-CoV-2 and wanting support. This was staffed by a team of social work, educational psychology and CAMHS staff who came together to be able to provide a rapid response. In Grampian and Orkney, a 'Psychological Resilience Hub' was established to provide a short course of psychological first aid to help individuals manage difficult feelings. Clinicians were available 6 days a week via video consultation. There were several other examples of creativeness and adaptability in supporting young people including a new podcast called 'Keep CAMHS and carry on' launched by a consultant psychiatrist. In both areas, staff described making garden visits, or going for outside walks to give supportive consultations safely.

So a number of [Trust] staff offered psychological first aid ... and a coaching approach around how we're supporting the leadership teams to have space to think about what they're managing when there are lots of people dying in their care homes or on their wards. (NE003)

\section{Changes in ways of working}

Alongside changes in pathways and service delivery, there were other less tangible but equally important 
changes in the ways people were working. Some interviewees described more integrated working and improved communications across previously subspecialist silos, across teams and organisations. The data also highlighted instances where communication processes were made more streamlined and efficient. An example is the improved use, in Tayside, of the information technology (IT) communication tool traditionally used for prescribing, which facilitated a new way of communicating between secondary and primary care. Staff were coming together in different ways, were attending remote meetings and working with new people including other clinicians, managers, academics and members of the armed forces. Interviewees reported an increased accessibility to meetings and consequently better attendance.

We managed to connect our infection specialists here in the centre of the very busy and big children's hospital, to our districts ... so that ... specialists were able to talk to specialists to get that understanding to help us feel connected, reassured. (NE001)

Beyond redeployments, staff were used more flexibly, working, for example, in new teams. In NENC Central, a change in the emergency department, with wards closed and a new respiratory ward created, meant training nursing staff to work with respiratory technology, mixing wards and recreating nursing teams to ensure mixed experiences on each ward. Across NOS, groups of staff (especially those who were shielding) were identified to work in different ways, for example, to run a remote outpatient service, or to triage patients for face-to-face assessments.

In NENC Central, interviewees described how the difficulty of filling rotas (due to many staff changes and absences) led to a change towards being self-managed, with staff invited to choose rather than being allocated shifts which may later need to be changed. Several interviewees talked about an affirmation of 'team spirit' and 'mutual support' which went across some traditional organisational boundaries.

I met a lot of different people that I had never met before and wards that I would never have a need to go on, understand all sorts of bits and pieces that I didn't know previously .... (NE013)

I've had to ask all these people to work beyond their boundaries. To work seven days a week ... Do work they're not used to. They've all adapted. (NOS009)

\section{Theme 2: perceived impact of these changes}

A wide range of positive and negative impacts of the pandemic response were identified by all interviewees. These were very similar across both regions, across the different services and among the different professions. They fell into three themes, summarised below and in table 3 .
Vast changes to working practices including online and remote working

Many positive impacts were reported, including the rapid roll-out of both new and old technologies (some of which had been requested for years); less time spent travelling; fewer and shorter meetings, and increased attendance at many; greater training opportunities, especially for those in more remote areas; and a disruption to the culture of 'presenteeism'. This generated a significant learning about what was and was not possible.

We have learned through these eightweeks that certain things that can easily be done online. (NOS009)

... we were able to certify deaths without having to see bodies ... we could in some of the cremation homes we were able to do a video consultation and just confirm that that's the body. (NE015)

However, participants also highlighted negative impacts, including loss of personal contact with children and families; less enjoyment and satisfaction from work; decreased team cohesion; staff well-being difficulties and staffing concerns; inequity in technology access and lack of equipment; and reduced training opportunities. Sometimes, the impact of reduced home visiting was ameliorated by using existing tools in new ways (eg, health visitors in NOS discussed sending out a questionnaire (Ages and States Questionnaire) they usually would have gone through in person), or by using tools such as pulse oximeters, spirometers and thermometers more extensively at home.

You are stuck looking at a screen day in day out. And it is really, really tiring and quite mentally draining having to concentrate for so long on a screen. (NOS018)

I guess what has happened is that they [parents] think nothing of messaging me at a weekend. That is the downside. (NOS003)

\section{Freedom for staff and opportunity for staff-driven change}

Participants highlighted a reduction in bureaucracy that usually stifles innovation; being listened to more by decision makers; having space to try out new things; less rigidity in how work is done; a greater opportunity to personalise service delivery for individual children/ families; increased collaboration and integrated working between professionals and across geographies; and staff going 'above and beyond'. Attitudes also changedboth organisational and individual-particularly towards online, remote and more flexible working. Participants also suggested that the exhausting pace of change and the increased workloads for many were unsustainable over time.

To be very honest ... I actually appreciated it to some extent because it meant, for me, to focus on action, to focus on something which is very imminent and very urgent. And I could actually kind of put off all the stuff which was, from my point of view, just the 
Table 3 Theme 2: perceived positive and negative impacts of early SARS-CoV-2 response on paediatric services in North of Scotland and North of England

\begin{tabular}{|c|c|c|}
\hline Subthemes & Positive impacts & Drawbacks \\
\hline $\begin{array}{l}\text { Vast } \\
\text { changes } \\
\text { to working } \\
\text { practices } \\
\text { including } \\
\text { online and } \\
\text { remote } \\
\text { working }\end{array}$ & $\begin{array}{l}\text { Rapid roll-out of new technology. } \\
\text { Less travel for staff, including for attending } \\
\text { regional meetings. } \\
\text { Disruption to 'presenteeism' culture. } \\
\text { Fewer and shorter meetings, and increased } \\
\text { attendance at some. } \\
\text { Greater training opportunities - especially for } \\
\text { those in remote areas. }\end{array}$ & $\begin{array}{l}\text { Loss of personal contact with children and families. } \\
\text { Work being less enjoyable. } \\
\text { Decreased team cohesion. } \\
\text { Inequity in technology access and lack of equipment. } \\
\text { Reduced training opportunities. }\end{array}$ \\
\hline $\begin{array}{l}\text { Freedom } \\
\text { for staff and } \\
\text { opportunity } \\
\text { for staff- } \\
\text { driven } \\
\text { change }\end{array}$ & $\begin{array}{l}\text { Reduced bureaucracy stifling innovation. } \\
\text { Decision makers listening to frontline staff. } \\
\text { Space to try out new things. } \\
\text { Staff feeling more flexible-less rigid approaches } \\
\text { to work. } \\
\text { Ability to personalise services for child and family } \\
\text { needs. } \\
\text { Increased collaboration, integrated working } \\
\text { between professionals and across geographies. } \\
\text { Staff going 'above and beyond'. }\end{array}$ & $\begin{array}{l}\text { Change fatigue. } \\
\text { Increased workload. }\end{array}$ \\
\hline $\begin{array}{l}\text { Perceived } \\
\text { impact on } \\
\text { children and } \\
\text { families }\end{array}$ & $\begin{array}{l}\text { Less travel for children and families. } \\
\text { Can reduce geographical inequity. } \\
\text { Opportunity to increase self-care. } \\
\text { Reduced wasted appointments and increased } \\
\text { (online) access to children. }\end{array}$ & $\begin{array}{l}\text { Reduced effectiveness of online working for some } \\
\text { elements of care. } \\
\text { Services stopping leading to missed diagnoses, poorer } \\
\text { care, building up of waiting lists. } \\
\text { Major concerns regarding children and young people's } \\
\text { well-being and hearing children and young people's } \\
\text { voices. } \\
\text { Difficulties of only one accompanying adult per child. } \\
\text { Concerns around privacy for online consultations. } \\
\text { Concerns regarding parental well-being. }\end{array}$ \\
\hline
\end{tabular}

bureaucratic nonsense and really focus on what was important at that point. (NE007)

Now I feel like I am actually doing the things that I was supposed to be doing before, because I've got time to do those things, which includes background work, includes like holistic care, like you know, letters to GPs to check physical health for some reason, or ... I don't know if I'm making sense, but the workload I had before was totally unrealistic. (NE006)

It was actually really nice at the beginning of the pandemic when there wasn't as many meetings. I felt I could really get on with work. (NOS001)

You know what I think has been really good. It has allowed people to be creative. (NOS009)

\section{Perceived impact on children and families}

Participants noted that many families benefited from the reduced travel necessitated by virtual appointments, which could also help reduce geographical inequity and reduce wasted appointments. Positive opportunities to increase self-care and management at home were also realised. However, interviewees voiced concerns relating to reduced effectiveness of online delivery for some elements of care; missed diagnoses, poorer care and the build-up of waiting lists due to services stopping; child/ young person well-being and the ability to hear children's voices; privacy for online consultations, especially for older children; and parental well-being.

Obviously there is a safeguarding dimension to it as well, not seeing as many children as we have done in the past .... (NE009)

... the parents are much more relaxed. Some children are very relaxed in their home environment and they interact better compared to hospital. (NOS015)

I suppose from my perspective, a lot of what I end up doing relies on having collaborative therapeutic relationships with children and parents who are in dire circumstance and doing things and asking the families counter intuitive things to treat their children and get them better. That is really hard to do on a video call. (NOS011)

\section{DISCUSSION}

This study explored the impact of the SARS-CoV-2 pandemic response on paediatric services in two regions of the UK using qualitative interviews with healthcare providers and managers. The data, collected between the UK's first and second waves of SARS-CoV-2, showed that 
the pandemic response led to multiple innovations that created new ways of relating, doing, organising, framing and knowing. ${ }^{10}$

The rapid adoption of digital technology in health service delivery and surge in patients' uptake of remote health services have been noted elsewhere. ${ }^{11}{ }^{12}$ This study identified rapid changes in communication between individuals, and in consultation types, including the introduction of new technologies. Clinical consultations were increasingly offered in a new flexible and hybrid way, with options for telephone, virtual and face-to-face consultations, according to clinical need, service users' preferences and the issue to be discussed. For many cases, this represented a new type of triaging so that no one attended a care environment (particularly an acute setting), without a prior remote clinical assessment. The largely positive perspectives on this from interviewees, with the dissipation of many former anxieties, are reflected in the existing literature. ${ }^{13-15}$ Indeed, telemedicine use in paediatrics has increased in recent years, and a recent systematic review of 11 randomised controlled trials has suggested that telemedicine services are comparable to or better than in-person services for the general public and paediatric care. ${ }^{16}$ However, in the webinar discussion, participants focused on the limitations of online consultations, including the issues of privacy and family preferences, as well as the 'digital divide'. ${ }^{17}$ Our study highlighted there was, for some, a shift in the balance of responsibility from practitioners to parents/ carers. With that came new ways of relating, perhaps with additional support being offered and parents/carers and practitioners working together differently. The use of new technologies that support telemedicine is likely to continue to grow. Further research would need to explore what works well for whom, and in what contexts, as well as the many unknowns relating to inequality and unintended consequences.

The roll-out of Microsoft Teams for online meetings influenced the ability to network and communicate outside of practitioners' local areas and affected the way in which some work was done, since online meetings do not mimic in-person meetings. New ways of communicating extended to other aspects of information sharing and working together, for example, with some traditional processes (eg, the dictation of letters) changed, and with joint working (eg, on a policy) improved through easier file sharing within teams. This finding is consistent with other discussions of changes seen during the pandemic, including how digitisation during SARS-CoV-2 has offered benefits to GPs, such as the ability to share documents safely with service users ${ }^{13}$ and acceleration of electronic prescribing services in general practice. ${ }^{14}$ These new ways of communicating and working together may offer advantages, for example, in terms of efficiency, flexibility and staff support, particularly as the NHS seeks to 'build back' following the pandemic. However, more work is needed to understand how to embed the positive changes and make them sustainable for the future.
The pandemic response saw considerable flexibility introduced to ways of organising. Staff were deployed and tasked in different, more fluid and more flexible ways. The need for this is likely to continue given the reduced numbers of available staff due to high rates of sickness and burnout among health workers as new variants emerge. ${ }^{18}$ Many people were relating more across a 'whole system', blurring traditional divisional boundaries, improving relationships and making new connections. Individuals and teams were galvanised around a more pressing shared purpose (to contain the spread of the virus) and so were thinking about capacity and need across entire organisations, and across localities and regions, rather than within their own usual silo. Some of the innovations that emerged reflected this understanding of the interdependent relationships between different teams/ parts of the system, and what can be done in one part, for example, to relieve pressure in another. This new way of relating and an acceleration in collaborative and integrated methods of working is supported by the existing literature. For example, in North Central London, major systemic changes were seen to take place in less than 3 weeks, with excellent collaborative work between all relevant stakeholders. ${ }^{19}$ In France, similar coordinated efforts across different parts of the system were evidenced to meet the challenges of SARS-CoV-2 and maintain adequate health services during the pandemic. ${ }^{20}$ Participants in our webinar said they wanted to retain these new ways of relating to others; however, such changes may be challenging to sustain. ${ }^{13} 14$

There is no doubt that governance altered during the response; many rules and norms were changed, new processes and systems were rapidly created, accountabilities shifted. In some cases, this was a refreshing experience for staff; change happened much more quickly than usual. However, others pointed to missing more usual involvement, consultation and nuanced decision-making. This new, empowering 'bottom-up' way of working, which meant a culture shift and relief of 'bureaucratic barriers', was also found in the literature. For example, a Health Foundation report discussed the same 'can do' attitude as described here, and a breaking through of so-called 'organisational inertia'. ${ }^{13}$ Others describe rapid service redesign in this period through a healthcare management science lens, with focus on a novel inflammatory condition linked to SARS-CoV-2 in children. ${ }^{21}$ The impact of the pandemic on the culture and climate of NHS organisations could be a fascinating area of future research, with potential importance for staff empowerment and subsequent individual and organisational outcomes. The Royal College of Paediatrics and Child Health 'Reset, Restore, Recovery' principles offer a potential blueprint. ${ }^{22}$

It was clear in the data that challenging situations were framed as opportunities for change. There was a remarkable positivity coming through the findings, despite the stress and anxiety many staff were feeling. A notable opportunity was in challenging pre-existing mindsets and 'normal' ways of doing things. For some, 
the focus on 'the way we have always worked' shifted. This allowed staff to review services and ways of working through a new lens and allowed interviewees to see preexisting problems more clearly. The data highlighted that some priorities changed because of the changing situation, and because of the changing perspectives on the situation. The dynamic atmosphere created during the pandemic response, which seemed to allow a focus on 'doing' and removed some of the traditional bureaucratic barriers, was something that practitioners wanted to retain. It encompassed a new-found trust and provided a degree of freedom to work in different ways, which was empowering-particularly to interviewees in NENC. This culture shift and empowerment of staff was also reported by the $\mathrm{NHS}^{14}$ and incorporated in the developing 'People Plan'. ${ }^{23}$ As noted in Lewis et al, ${ }^{13}$ NHS staff are sometimes portrayed as being 'the stumbling block to change'; the pandemic response has helped to demonstrate that they can indeed lead radical change, if they are trusted and empowered to do so. In our webinar discussion, however, participants shared that they believed systemic barriers were already reappearing and that the 'honeymoon' was over.

\section{Strengths and limitations}

A strength of this study lies in the rigorous way in which we gathered and analysed qualitative in-depth data on the experiences of a purposively sampled range of child healthcare providers across two large geographical regions in the UK. However, it should be noted that it presents a snapshot in time, at a time of ongoing significant change. At the time of writing, the COVID-19 pandemic has continued for a year beyond the last of our interviews. Insight into more staff perspectives from 2021 could be gained by repeating our methodology in our two regions and others across the UK. The pressures of selfisolation rules, social distancing, managing the backlog of work and chronic fatigue may have changed staff perspectives. What is uncertain is whether the changes described here (including IT and teamworking) may have lessened such pressures which are in addition to those present before the pandemic. Further research is required to investigate staff experiences and perspectives across the UK using qualitative methods to ensure staff perspectives are explored in depth, and quantitative methods such as cross-sectional surveys to ensure more voices are captured for greater generalisability of findings.

\section{CONCLUSION}

The roll-out of technology and the new learning developed in relation to delivering services and clinician support remotely is of great importance. More isolated staff have much to gain from being more digitally connected to others outside of their area. In both regions, the emphasis on collaboration and integrated ways of working, the pooling of resources, the greater flexibility in staff roles and the cross-fertilisation of ideas seen during the pandemic response can help deliver more effective, efficient and sustainable services. The reported changes illustrated the start of a potential move to more whole system approaches. The new values and cultural shift that emerged, for example, around strategic leadership enabled flexibility, agility and collaboration which was empowering and positive for staff. The new level of trust, freedom and space to innovate would be valuable for the NHS to sustain in future years, to create a healthier, more sustainable future.

\section{Author affiliations}

${ }^{1}$ Centre for Health Services Studies, University of Kent, Canterbury, UK

${ }^{2}$ Faculty of Health Sciences and Sport, University of Stirling, Stirling, UK

${ }^{3}$ Faculty of Health Sciences and Wellbeing, University of Sunderland, Sunderland, UK ${ }^{4}$ Population Health Sciences Institute, Newcastle University, Newcastle upon Tyne, UK

${ }^{5}$ Great North Children's Hospital, Newcastle upon Tyne, UK

${ }^{6}$ Child Health and Wellbeing Network, North East and North Cumbria Integrated Care System, Middlesbrough, UK

${ }^{7}$ Department of Child Health, University of Aberdeen, Aberdeen, UK

${ }^{8}$ Women and Children Division, NHS Grampian, Aberdeen, UK

\section{Twitter Floor Christie-de Jong @floorchristie}

Acknowledgements We are grateful to Emilia Soulsby and Laura Richardson who supported the data collection in NENC, to Chris Drinkwater who served as expert advisor throughout and to Dr Mike McKean, clinical lead for the NENC network, for his encouragement and initial connection between the two regions to conduct this research. Also thanks to all those who participated in interviews and in our webinar where findings were discussed.

Contributors EWG, SB, FC-dJ, HC and ST made substantial contributions to the conception and design of the work and to the acquisition, analysis and interpretation of data for the work. EWG, FC-dJ and SB were responsible for initial analysis of data, with subsequent input on analysis and interpretation from $\mathrm{HC}$ and ST. EWG drafted the work and all authors revised it critically for important intellectual content. All authors gave final approval of the version to be published and agree to be accountable for all aspects of the work. EWG is responsible for the overall content as the guarantor.

Funding The authors have not declared a specific grant for this research from any funding agency in the public, commercial or not-for-profit sectors.

Competing interests None declared.

Patient consent for publication Not applicable.

Ethics approval This study involves human participants and was approved by the University of Kent School of Social Policy, Sociology and Social Research Ethics Committee (reference number SRCEA ID 265). Participants received a copy of the information sheet and consent form prior to the interview. Consent forms were electronically signed prior to interview and/or confirmed (and recorded) orally at the start of the interview, following a reminder of their rights. Research approval was granted by the relevant employing organisations of the staff approached for interview. Participants gave informed consent to participate in the study before taking part.

Provenance and peer review Not commissioned; externally peer reviewed.

Data availability statement Data are available upon reasonable request. Deidentified participant data are available upon reasonable request from EWG (https://orcid.org/0000-0002-4151-5911) for research purposes only.

Supplemental material This content has been supplied by the author(s). It has not been vetted by BMJ Publishing Group Limited (BMJ) and may not have been peer-reviewed. Any opinions or recommendations discussed are solely those of the author(s) and are not endorsed by BMJ. BMJ disclaims all liability and responsibility arising from any reliance placed on the content. Where the content includes any translated material, BMJ does not warrant the accuracy and reliability of the translations (including but not limited to local regulations, clinical guidelines, terminology, drug names and drug dosages), and is not responsible for any error and/or omissions arising from translation and adaptation or otherwise. 
Open access This is an open access article distributed in accordance with the Creative Commons Attribution Non Commercial (CC BY-NC 4.0) license, which permits others to distribute, remix, adapt, build upon this work non-commercially, and license their derivative works on different terms, provided the original work is properly cited, appropriate credit is given, any changes made indicated, and the use is non-commercial. See: http://creativecommons.org/licenses/by-nc/4.0/.

\section{ORCID iDs}

Erica W Gadsby http://orcid.org/0000-0002-4151-5911

Floor Christie-de Jong http://orcid.org/0000-0001-5275-8030

\section{REFERENCES}

1 Bhopal SS, Bagaria J, Olabi B, et al. Children and young people remain at low risk of COVID-19 mortality. Lancet Child Adolesc Health 2021;5:e12-13.

2 Bhopal S, Bagaria J, Bhopal R. Children's mortality from COVID-19 compared with all-deaths and other relevant causes of death: epidemiological information for decision-making by parents, teachers, clinicians and policymakers. Public Health 2020;185:19-20.

3 Butler P. Child poverty increases in England across the North and Midlands. The guardian, 2020.

4 Hirsch D, Stone J. Local indicators of child poverty after housing costs, 2018/19. Summary of estimates of child poverty after housing costs in local authorities and parliamentary constituencies, 2014/152018/19, 2020

5 Parker C, Scott S, Geddes A. Snowball sampling. In: Atkinson P, Delamont S, Cernat JW, eds. SAGE research methods foundations. SAGE Publications Ltd, 2019.

6 Coronavirus (COVID-19): Scotland's route map [online], 2020. Available: https://www.gov.scot/collections/coronavirus-covid-19scotlands-route-map/ [Accessed 24 Apr 2020].

7 Coronavirus guidance for clinicians and NHS managers [online], 2020. Available: https://www.england.nhs.uk/coronavirus/ [Accessed 24 Apr 20].

8 Ritchie J, Spencer L. Qualitative data analysis for applied policy research. In: Bryman A, Burgess RG, eds. Analyzing qualitative data. Oxon: Routledge, 1994: 173-94.
9 Creswell JW, Plano Clark VL, Gutmann M. Advanced mixed methods research designs. In: Tashakkori A, Teddlie C, eds. Handbook of mixed methods in social and behavioral research. Thousand Oaks, CA: Sage, 2003: 209-40.

10 Haxeltine A, Avelino F, Pel B. A framework for transformative social innovation (transit working paper \# 5). transit: EU SSH.2013.3.2-1 grant agreement NO: 6131692016.

11 Hutchings A. The impact of covid-19 on the use of digital technology in the NHS. Nuffield Trust, 2020.

12 Badawy SM, Radovic A. Digital approaches to remote pediatric health care delivery during the COVID-19 pandemic: existing evidence and a call for further research. JMIR Pediatr Parent 2020;3:e20049.

13 Lewis R, Pereira P, Thorlby R. Understanding and sustaining the health care service shifts accelerated by COVID-19. London: Health Foundation, 2020.

14 Powis S, Hassell C. Clinical innovations during COVID-19 (board paper). NHS England and NHS Improvement, 2020.

15 Schinasi DA, Foster CC, Bohling MK, et al. Attitudes and perceptions of telemedicine in response to the COVID-19 pandemic: a survey of naïve healthcare providers. Front Pediatr 2021;9:647937.

16 Shah AC, Badawy SM. Telemedicine in pediatrics: systematic review of randomized controlled trials. JMIR Pediatr Parent 2021;4:e22696.

17 People's Health Trust. The digital divide, 2021.

18 Gemine R, Davies GR, Tarrant S, et al. Factors associated with workrelated burnout in NHS staff during COVID-19: a cross-sectional mixed methods study. BMJ Open 2021;11:e042591.

19 Goldin J, Hudson L. 5 system changes in response to the COVID-19 pandemic for adolescent mental health crisis admissions in north/ central London. Arch Dis Child 2020;105:A2.

20 Julia C, Saynac Y, Le Joubioux C, et al. Organising community primary care in the age of COVID-19: challenges in disadvantaged areas. Lancet Public Health 2020;5:e313.

21 Cheung CR, Finnemore A, Handforth J, et al. Developing new models of care at speed: learning from healthcare redesign for children with COVID-related multisystem inflammation. Arch Dis Child 2021;106:528-32.

22 Royal College of Paediatrics and Child Health. Reset, restore, recover. RCPCH principles for recovery. RCPCH, 2020.

23 NHS England. We are the NHS: People plan for 2020/2021 - action for us all, 2020. 